\title{
THE EVOLUTION OF LONG DISTANCE RUNNING AND SWIMMING
}

\author{
J.D. CHARLES ${ }^{1} \&$ A. BEJAN ${ }^{2}$ \\ ${ }^{1}$ Boeing Commercial Airplanes - Advanced Structural Architectures R\&D, \\ 6900 E Green Lake Way North, Seattle, WA 98115, USA. \\ ${ }^{2}$ Duke University, Department of Mechanical Engineering and Materials Science, Box 90300, \\ Durham, NC 27708-0300, USA.
}

\begin{abstract}
The modern evolution of long distance running and swimming is documented statistically: body mass (M), height $(\mathrm{H})$, slenderness $(\mathrm{S})$, and winning speed $(\mathrm{V})$. In long distance running $(10,000 \mathrm{~m}), \mathrm{M}, \mathrm{H}$, and $\mathrm{S}$ are decreasing: these trends contradict the trends in short distance running $(100 \mathrm{~m})$. In long distance swimming (1,500 $\mathrm{m}$ freestyle), the trends are similar to short distance $(100 \mathrm{~m}$ freestyle): $\mathrm{H}$ and $\mathrm{V}$ are increasing. The parallel trends in long versus short distance swimming, and conflicting trends in long versus short distance running are due to dehydration, which is limiting only in long distance running. The speed records ratio running/swimming for long distance sports is decreasing at the same rate as for short distance sports. Running and swimming are subject to speed 'ceilings' $\left(\mathrm{V}_{\max }\right)$ dictated by physics: the current record speeds in running and swimming are close to $\frac{1}{2} \mathrm{~V}_{\max }$.
\end{abstract}

\section{INTRODUCTION}

Animal locomotion in water, air, and on land is united by body-size scaling rules that are as universal as all the other scaling rules of animal design (e.g., metabolism, respiration, organ sizes). These phenomena of scaling have stimulated an intense activity, which is reviewed regularly, for example, in Refs. [1-5].

A recent outgrowth of the progress on animal scaling is the study of sports evolution, particularly, the evolution of speed records in running and swimming [6,7]. These studies confirm that what is known about animal scaling can also be used in a predictive sense in the evolution of speed sports. At the same time, speed sports provide a laboratory (a small, carefully defined sample) in which to observe the phenomenon of evolution during our life time.

The speed sports that have been documented and explained so far in evolutionary design terms are the short distance events, $100 \mathrm{~m}$ dash and $100 \mathrm{~m}$ freestyle, men and women [6, 7]. In this paper, we extend this study to long distance running and swimming, and unveil a major anomaly: the body sizes and heights of long distance runners have been decreasing, in contrast with the trends exhibited by short distance runners, and by short and long distance swimmers.

\section{LONG DISTANCE RUNNING}

To track the evolution of the record breakers in long distance running, we selected the $10 \mathrm{~km}$ run, because it is conducted under closely monitored conditions. Unlike the marathon, which is run through the streets of the host city, the $10 \mathrm{~km}$ race is held on a track inside the stadium in order to produce results that are much more consistent, as variables such as topography are eliminated.

The records and body measurements of the winners are compiled in Table 1. Several graphs are supported by this data, and they reveal clear evolutionary trends. The speed records are shown in Fig. 1a. The body mass (Fig. 1b) exhibited a downward trend during the past 80 years. Combining Figs $1 \mathrm{a}$ and $\mathrm{b}$ by eliminating the time as a variable we obtained Fig. 1c, which shows that higher speeds correlate with smaller bodies

$$
\mathrm{V} \cong 24.8 \mathrm{M}^{-0.34}
$$

(C) 2013 WIT Press, www.witpress.com

ISSN: 1755-7437 (paper format), ISSN: 1755-7445 (online), http://journals.witpress.com

DOI: $10.2495 / \mathrm{DNE}-\mathrm{V} 8-\mathrm{N} 1-17-28$ 


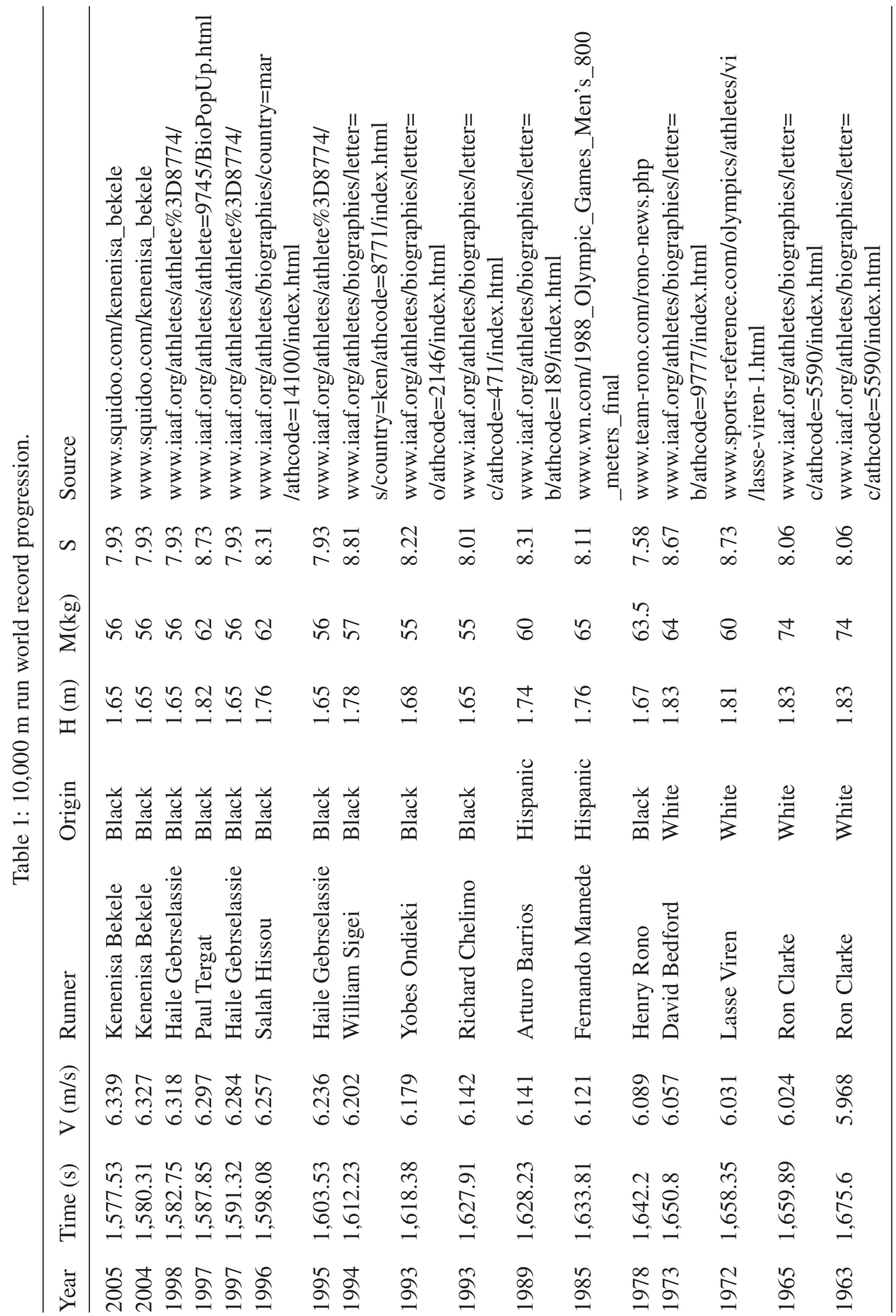




\begin{tabular}{|c|c|c|c|c|c|c|c|}
\hline 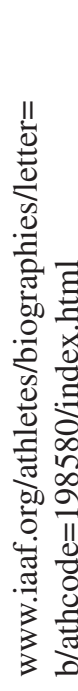 & 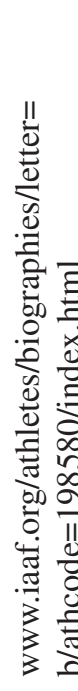 & 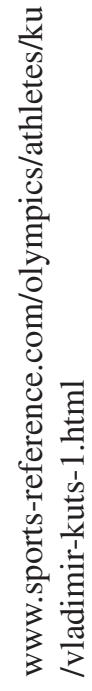 & 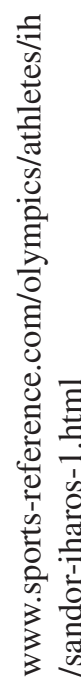 & 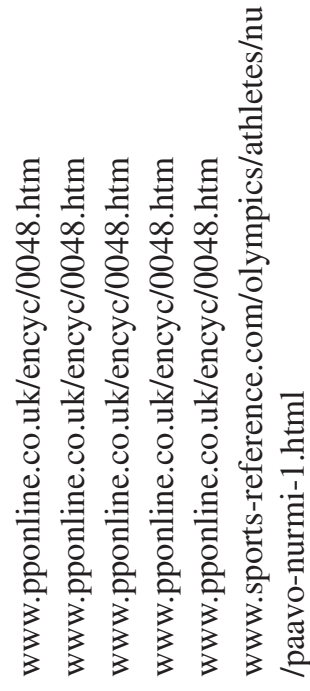 & 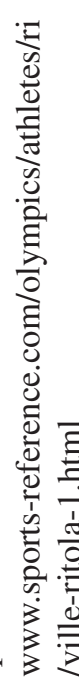 & 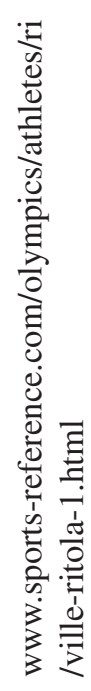 & 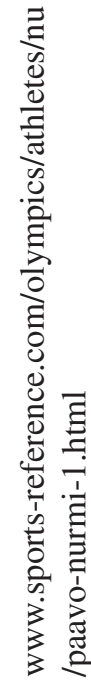 \\
\hline$\underset{\infty}{\stackrel{+}{\infty}}$ & $\underset{\infty}{\stackrel{+}{\infty}}$ & $\stackrel{n}{\stackrel{n}{r}}$ & $\stackrel{+}{\sim}$ & $\stackrel{n}{r} \stackrel{r}{r} \stackrel{r}{r}$ & $\stackrel{\infty}{\infty}$ & $\stackrel{\infty}{\infty}$ & $\hat{a}$ \\
\hline$\tilde{6}$ & $\tilde{6}$ & $\sqrt[n]{1}$ & 6 & 아유유 & $\infty$ & $\infty$ & 6 \\
\hline$\stackrel{?}{\stackrel{2}{2}}$ & $\stackrel{?}{\stackrel{2}{2}}$ & $\stackrel{-}{i}$ & $\stackrel{-}{I}$ & 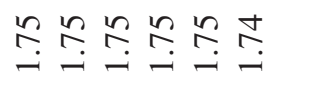 & $\stackrel{n}{\stackrel{n}{i}}$ & $\stackrel{n}{\stackrel{n}{i}}$ & $\stackrel{5}{5}$ \\
\hline$\frac{\mathscr{C}}{3}$ & 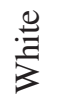 & $\frac{\mathscr{\varrho}}{3}$ & 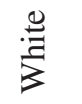 & 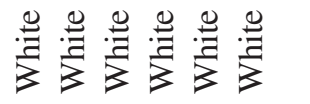 & $\stackrel{\frac{0}{3}}{3}$ & $\stackrel{\frac{0}{2}}{3}$ & $\frac{0}{3}$ \\
\hline 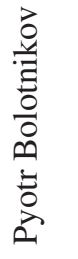 & $\begin{array}{l}\overrightarrow{0} \\
: \overrightarrow{0} \\
\vdots \\
0 \\
0 \\
0 \\
0 \\
\vdots \\
0 \\
0 \\
0\end{array}$ & 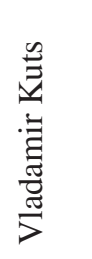 & 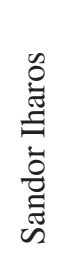 & 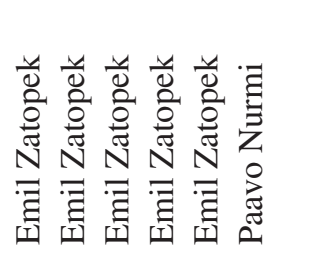 & $\begin{array}{l}\frac{\pi}{0} \\
\stackrel{0}{2} \\
0 \\
0 \\
=0\end{array}$ & $\begin{array}{l}\frac{\pi}{0} \\
\stackrel{0}{2} \\
0 \\
0 \\
\frac{0}{1}\end{array}$ & 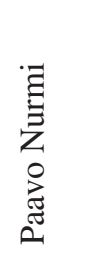 \\
\hline $\begin{array}{l}\hat{\infty} \\
\infty \\
\dot{n}\end{array}$ & $\begin{array}{l}\infty \\
\infty \\
\infty \\
i\end{array}$ & $\begin{array}{l}0 \\
\infty \\
\infty \\
i\end{array}$ & $\begin{array}{l}\underset{D}{0} \\
\infty \\
i\end{array}$ & 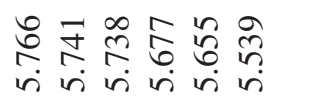 & in & $\begin{array}{l}\vec{n} \\
\stackrel{n}{n}\end{array}$ & $\underset{⿱ 亠 m}{r}$ \\
\hline $\begin{array}{l}n \\
\infty \\
0 \\
0\end{array}$ & $\begin{array}{l}\infty \\
\infty \\
\stackrel{\infty}{0} \\
-\end{array}$ & $\underset{\stackrel{+}{\circ}}{\stackrel{+}{\pi}}$ & 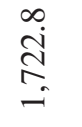 & 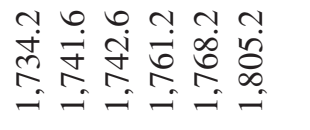 & 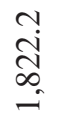 & 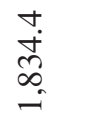 & $\stackrel{n}{\infty}$ \\
\hline బิ & ஜ & $\stackrel{\circ}{2}$ & $\stackrel{\circ}{2}$ & 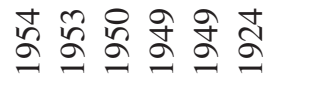 & 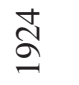 & 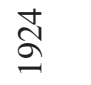 & $\bar{v}$ \\
\hline
\end{tabular}



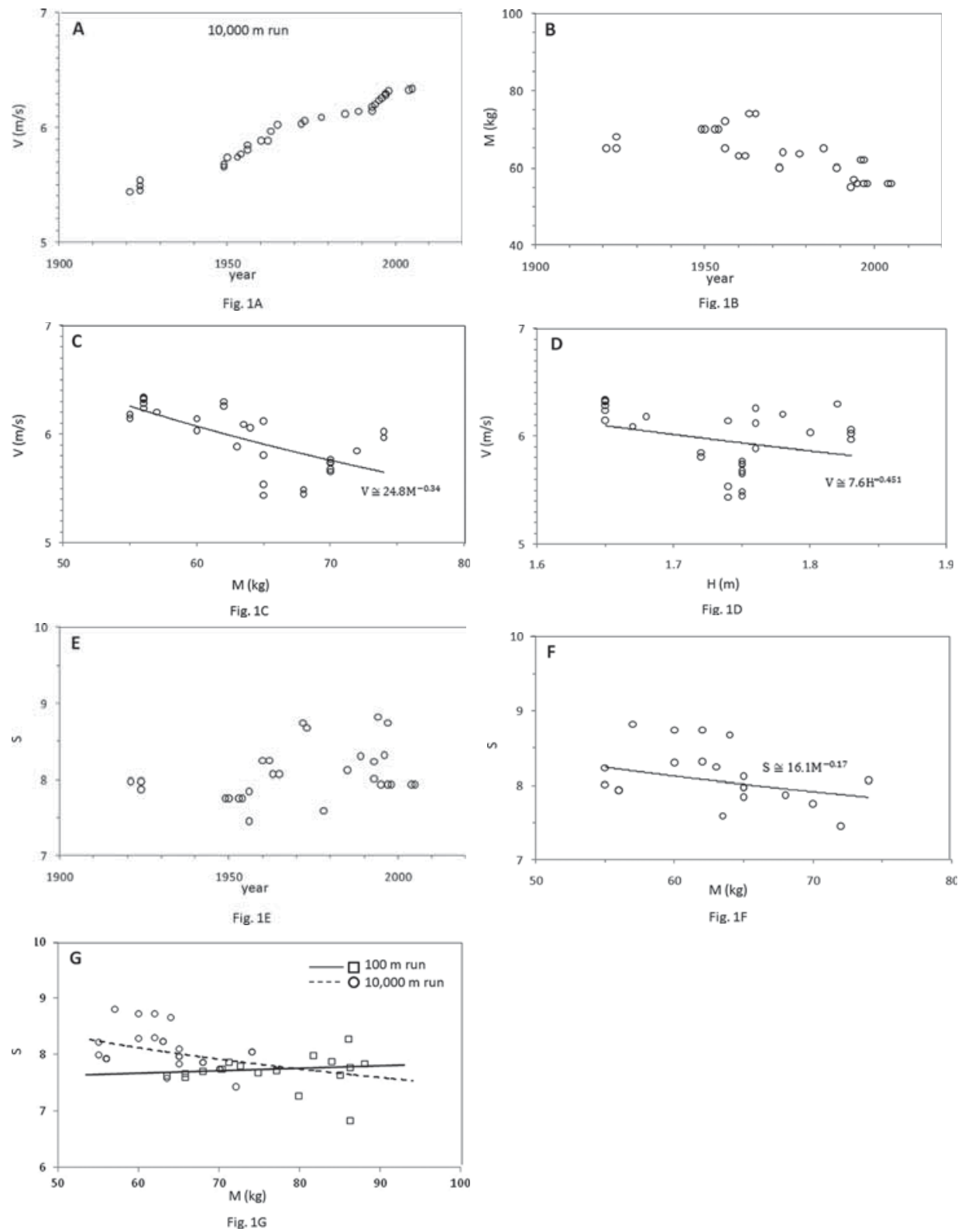

Figure 1: The evolution of long distance running:
a. Record speeds versus time.
b. Body mass versus time.
c. Record speeds versus body mass.
d. Record speeds versus body height.
e. Body slenderness versus time.
f. Body slenderness versus body mass.
g. Comparison between body slenderness versus mass in long distance and short distance running. 
where $\mathrm{V}$ and $\mathrm{M}$ are expressed in $\mathrm{m} / \mathrm{s}$ and $\mathrm{kg}$, respectively. This correlation was obtained by power law regression, and it is statistically significant because its $\mathrm{P}$ value is 0.0001 (less than 0.05 so the null hypothesis can be rejected $[8,9])$, and $\mathrm{R}^{2}=0.466$. This trend is the opposite of what we found in sprint (the $100 \mathrm{~m}$ run) [6], where body sizes have been increasing in time.

The effect of size is reinforced by Fig. 1d, which shows the athlete's height on the abscissa. The power law correlation is

$$
\mathrm{V} \cong 7.6 \mathrm{H}^{-0.451}
$$

with $\mathrm{P}=0.048$ and $\mathrm{R}^{2}=0.125$. The faster long distance runners tend to be shorter. This trend is the opposite of the trend found in short distance running [6], where the winners tend to be taller over time.

In our study of the evolution of sprint in running and swimming [6,7], we proposed a twoparameter description of the body geometry: one parameter for body size ( $\mathrm{M}$, or $\mathrm{H})$, and a second parameter for body shape, the body slenderness

$$
\mathrm{S}=\frac{\mathrm{H}}{\mathrm{L}}
$$

where $\mathrm{L}$ is the transversal dimension of the body, viewed as a cylinder of length $\mathrm{H}$ and diameter $\mathrm{L}$. The measured body mass $\mathrm{M}=\rho(\pi / 4) \mathrm{L}^{2} \mathrm{H}$ can be combined with the measured height $(\mathrm{H})$ to calculate the body slenderness when $\mathrm{M}$ and $\mathrm{H}$ are known,

$$
S=\left(\frac{\pi \rho \mathrm{H}^{3}}{4 \mathrm{M}}\right)^{1 / 2}
$$

where $\rho \cong 10^{3} \mathrm{~kg} / \mathrm{m}^{3}$ is the body density. The slenderness $\mathrm{S}$ was calculated from $\mathrm{M}$ and $\mathrm{H}$ and reported in Table 1. It is reported in Fig. 1e, which slows that the slenderness of long distance record breakers has an upward trend versus time. This agrees with the trend exhibited by the $S$ values of 100 m sprinters [6].

Combining Fig. 1e with Fig. 1b we obtained Fig. 1f, which shows that in the direction of greater speed (lower M, Fig. 1c) the slenderness increases as the body size decreases,

$$
\mathrm{S} \cong 16.1 \mathrm{M}^{-0.17}
$$

with $\mathrm{P}=0.038$ and $\mathrm{R}^{2}=0.150$. This trend is contrary to what we found in short distance running, where $\mathrm{S}$ increases with the body size [6]. This can be seen in Fig. 1g. The clash between the long distance and short distance trends is remarkable.

\section{LONG DISTANCE SWIMMING}

For long distance swimming, we tracked the evolution of speed records and body size and shape in $1,500 \mathrm{~m}$ freestyle. The data is presented in Table 2, and the analysis is captured in Figs 2a-f.

Figures $2 \mathrm{a}$ and $\mathrm{b}$ show the evolution of winning speeds and body sizes during the past one hundred years. The cross-plotting of these two figures as $V$ versus $M$ is shown in Fig. 2c. The power law regression analysis would yield an upward trend of $\mathrm{V}$ versus $\mathrm{M}$, but this is not statistically significant. The alternative is to plot the swimmer's height on the abscissa as shown in Fig. 2d, which shows that speeds increase with body height. This in agreement with the speed-height trend found in 


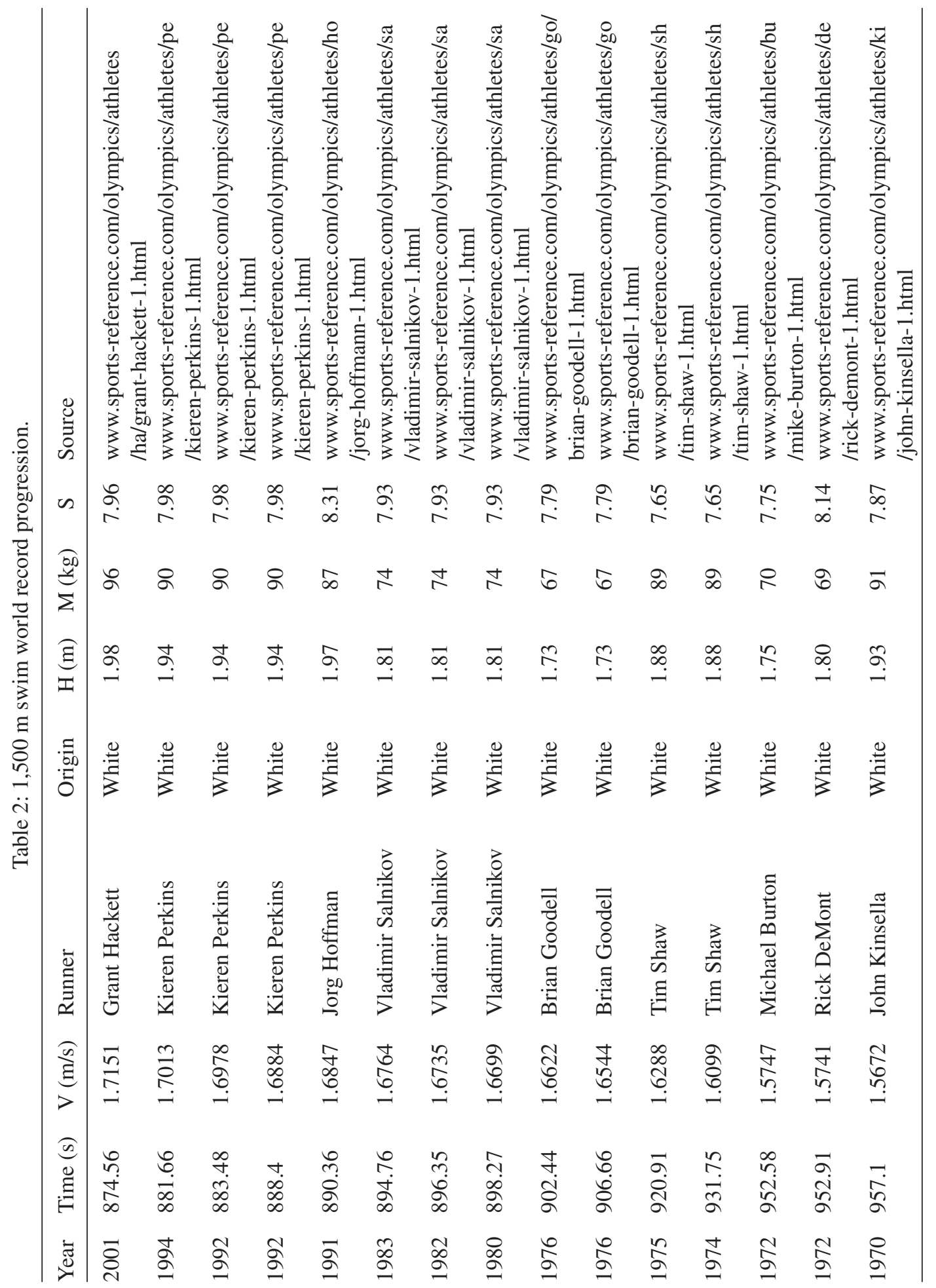




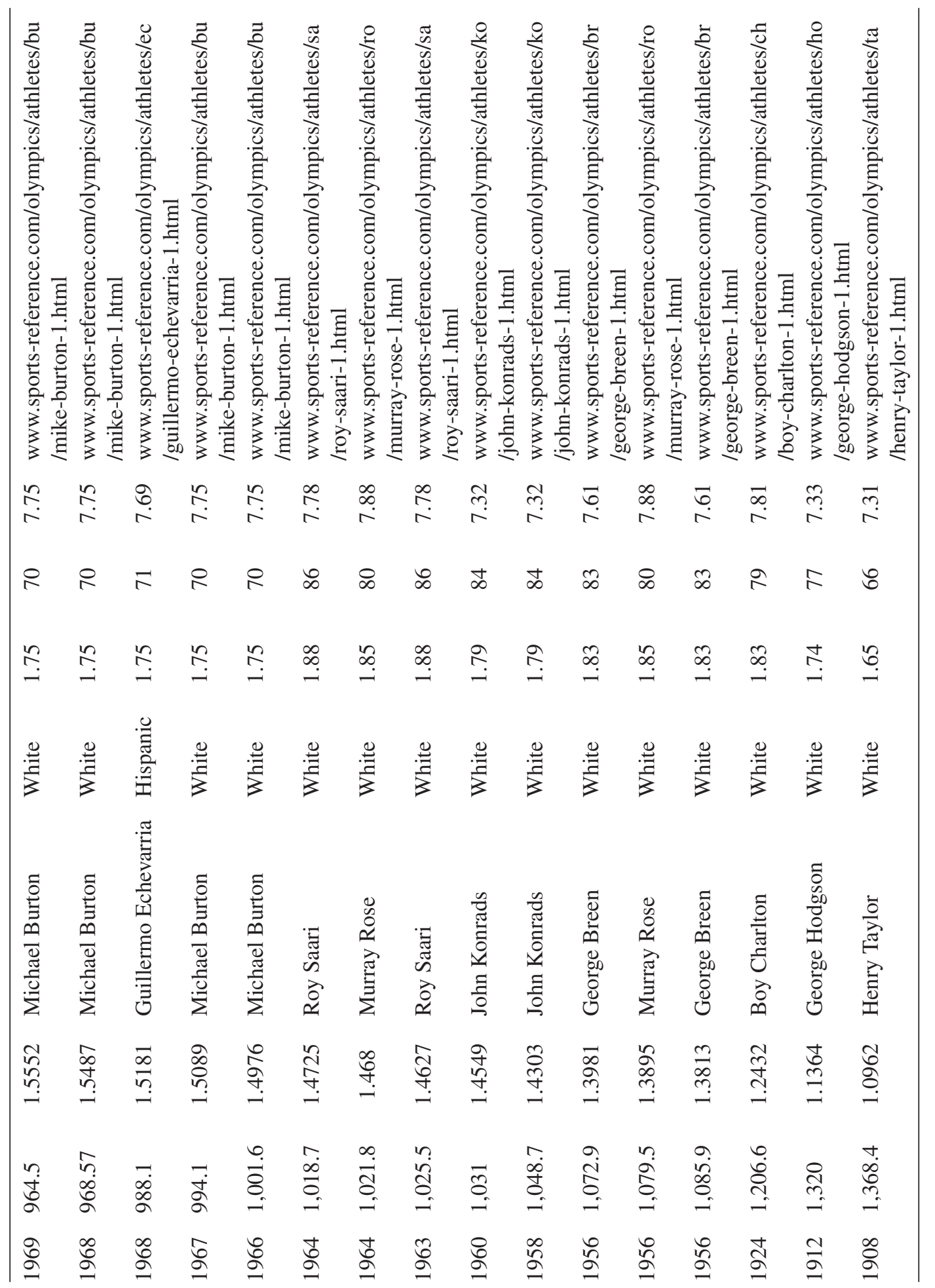



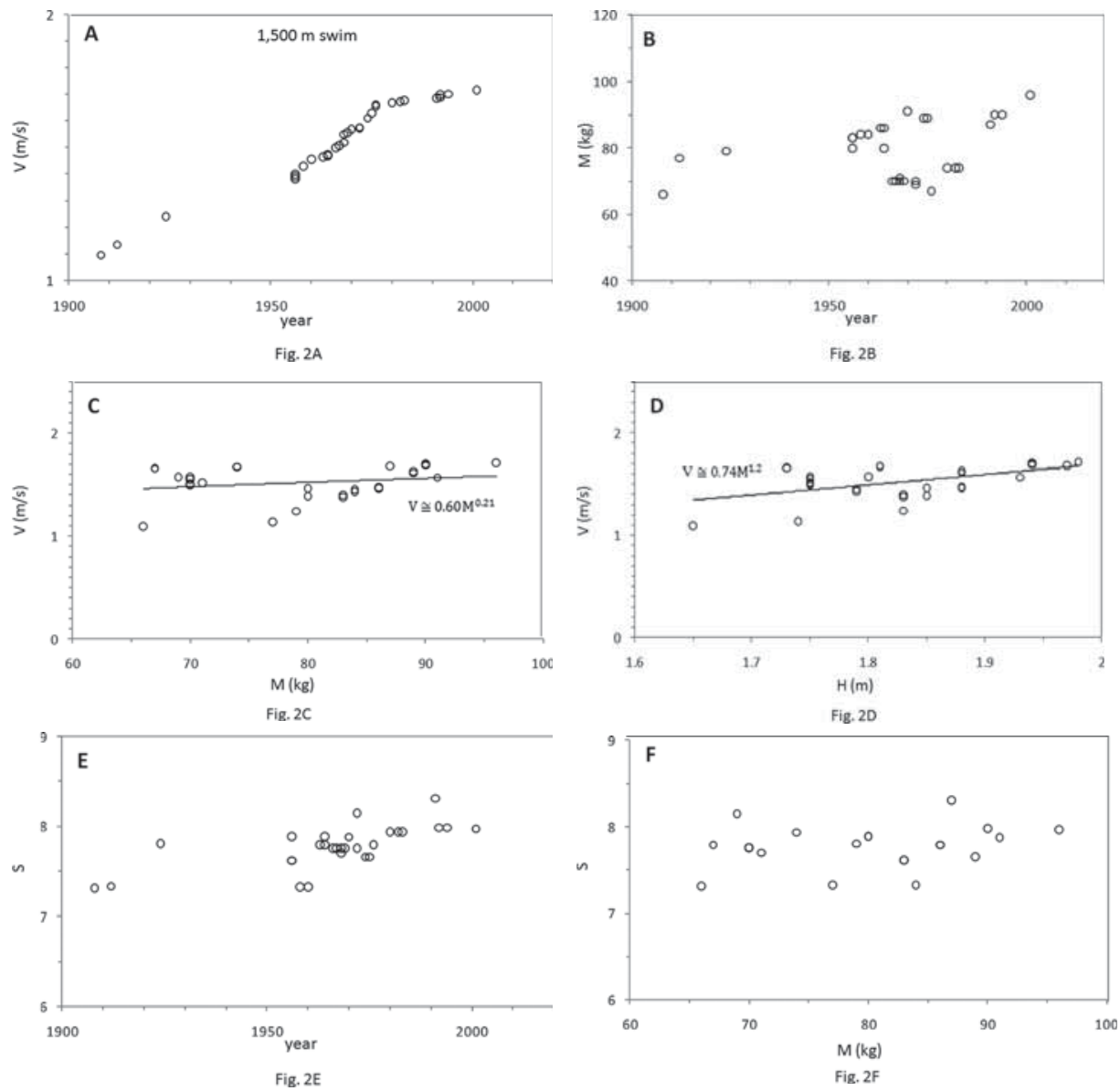

Figure 2: The evolution of long distance swimming:
a. Record speeds versus time.
b. Body mass versus time.
c. Record speeds versus body mass.
d. Record speeds versus body height.
e. Body slenderness versus time.
f. Body slenderness versus body mass.

$100 \mathrm{~m}$ freestyle [6], and in disagreement with long distance running (Fig. 1c). The power law correlation emerging from Fig. $2 \mathrm{~d}$ is

$$
\mathrm{V} \cong 0.74 \mathrm{H}^{1.2}
$$

and it is statistically significant, with $\mathrm{P}=0.006$ and $\mathrm{R}^{2}=0.229$.

Figure 2e shows that the body slendernesses of long distance swimming champions have been increasing in time. This is in agreement with Fig. 1e for long distance runners, but not with the corresponding data for short distance swimmers (100 m freestyle), which is inconclusive about the 
trend of S versus M (see Fig. 6a in Ref. [6]). Combining Figs. 2e and b we arrive at Fig. 2f, which shows the relative insensitivity of $\mathrm{S}$ to $\mathrm{M}$, which is in agreement with the corresponding trend found in short distance swimming (100 m freestyle [6]).

\section{DISCUSSION}

There are important differences between long distance and short distance running, and they demand an explanation. They are particularly intriguing because of the agreement between the long distance and short distance trends in swimming (Table 3).

The agreement between the evolution of long distance and short distance speed sports is more extensive. Noteworthy is the ratio between the winning speeds in long distance running and long distance swimming (Fig. 1a versus Fig. 2a), which evolves toward approximately 4, as shown in Fig. 3. This trend is similar to the corresponding ratio of speeds in $100 \mathrm{~m}$ dash versus $100 \mathrm{~m}$ freestyle [6]. This is the same ratio as between the speeds of all running animals divided by the speeds of all swimming animals [5].

Table 3: Comparison of the evolutionary trends of long distance running and swimming, versus the corresponding short distance trends.

\begin{tabular}{lcccccc}
\hline & \multicolumn{3}{c}{ Run } & & \multicolumn{2}{c}{ Swim } \\
\cline { 2 - 3 } \cline { 6 - 7 } & Short & Long & & Short & Long \\
\hline M versus time & $\uparrow$ & $\downarrow$ & & - \\
V versus M & $\uparrow$ & $\downarrow$ & & $\uparrow$ & - \\
V versus H & $\uparrow$ & $\downarrow$ & & $\uparrow$ & $\uparrow$ \\
S versus M & $\uparrow$ & $\downarrow$ & & - & - \\
\hline
\end{tabular}

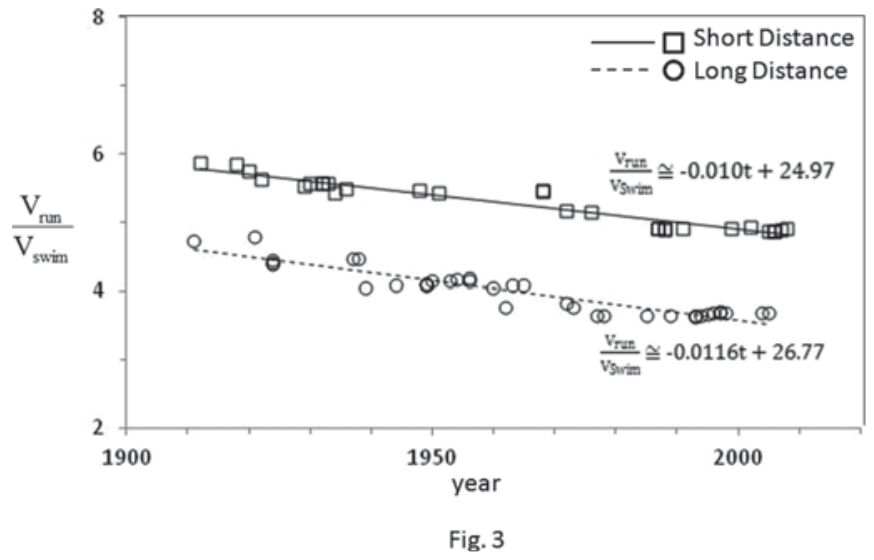

Figure 3: The evolution of the ratio of record running speed divided by the record swimming speed in long distance versus short distance events. 
Figure 3 also shows that the ratio $\mathrm{V}_{\text {run }} / \mathrm{V}_{\text {swim }}$ has been decreasing in time at the same rate for short and long distance competitions. This trend is correlated with statistical significance for short and long distance, respectively,

$$
\begin{array}{ll}
\frac{\mathrm{V}_{\text {run }}}{\mathrm{V}_{\text {swim }}} \cong-0.010 \mathrm{t}+24.97, & \left(\mathrm{P}=0.0001, \mathrm{R}^{2}=0.926\right) \\
\frac{\mathrm{V}_{\text {run }}}{\mathrm{V}_{\text {swim }}} \cong-0.0116 \mathrm{t}+26.77, & \left(\mathrm{P}=0.0001, \mathrm{R}^{2}=0.863\right)
\end{array}
$$

where $\mathrm{t}$ is the calendar year shown on the abscissa. The downward trend of $\mathrm{V}_{\text {run }} / \mathrm{V}_{\text {swim }}$ indicates that speeds are consistently increasing faster in swimming than in running, meaning that world records will likely continue to be broken more frequently in swimming than in running. The ratio $\mathrm{V}_{\text {run }} / \mathrm{V}_{\text {swim }}$ in long distance competitions is consistently smaller (by 20 percent) than in short distance competitions. This can be explained by the similar push to athletes' selection in a wider population and the effects of similarly effective training techniques. Swimming can improve more (faster) than running as it is an unnatural locomotion for humans, with a very low efficiency and thus, a great scope for improvement.

Another trend that agrees with short distance speed sports is the origin of the long distance athletes. Tables 1 and 2 show that in long distance running the winners now tend to be of African origin. In long distance swimming, they tend to be of European origin. This agrees with the trends that dominate the $100 \mathrm{~m}$ dash and $100 \mathrm{~m}$ freestyle, which were predicted based on the constructal theory of animal locomotion. Speed is dictated by the height from which the body mass falls, and in running the height is the position of the center of mass above the ground, while in swimming the height (of the shoulders above the water) is proportional to the distance from the center of mass to the top of the head [7]. Still, there is a difference in running: the short distance winners are of West African origin, and the long distance winners are of East African origin.

Table 3 suggests a way to explain why the evolution of long distance running is different than the evolution of long distance swimming, short distance running and short distance swimming. Specifically, the table raises three questions:

1. Why is the trend for body size $(\mathrm{H})$ downward for long distance running and upward for long distance swimming?

2. Why is the trend for body size $(\mathrm{H})$ the same for long distance swimming and short distance running and swimming?

3. Why does the size $(\mathrm{M}, \mathrm{H})$ of long distance runners decrease in time?

Needed is a single physics argument that answers all three questions. The answer is evident if we ask what is different between long distance running and long distance swimming. The difference is the ambient - air versus water - and this means that the phenomenon of body temperature control and loss of body water (dehydration) is a limiting factor in long distance running and not in swimming. Furthermore, the loss of body water is not a limiting phenomenon in swimming (long or short) because the outer surface of the skin of the swimmer is in chemical equilibrium with the water in the pool. La Fédération Internationale de Natation mandates a pool temperature range of $25-28^{\circ} \mathrm{C}$ for all international aquatic competitions, well below the average body temperature of $37.5^{\circ} \mathrm{C}[10]$. This temperature difference, combined with the chemical equilibrium of a swimmer's skin with the water in the pool, drastically reduces body heat and mass transfer (in the form of sweat) to the surrounding environment and mitigates the threat of dehydration during long distance swimming. The loss of 
body water is not a limiting phenomenon in short distance running because of the extremely short duration of the run. The loss of water by mass transfer from body to air needs time before it can impact the body water inventory.

The rate of water loss by mass transfer during an essentially fixed period (the time of running the $10,000 \mathrm{~m}$ race) is proportional to the size of the surface of contact between body and air. A smaller mass transfer rate (slower rate of dehydration) goes with a smaller surface, and this means a smaller body size (M, H). Furthermore, athletes with smaller body size have less muscle and fat. Muscle and fat act as insulators and raise the core body temperature, which in turn increases the heat and mass transfer rates (as body heat and sweat) between the skin and the air. In any size athlete, heat and mass transfer from the skin to the competition medium is required to keep the core body temperature constant. This answers question no. 3, but it seems to contradict the general trend that unites all locomotion (animals and speed sports), which is that larger bodies move horizontally at higher speeds. This general trend is correct, but it represents a broad view of bodies with locomotion lifetime, i.e., not under the threat of dehydration.

By questioning the speed-mass trend in long distance running, we learn that the loss of body water has a stronger effect on speed than the body size. The winning time $t$ over the long distance $\mathrm{L}$ is $\mathrm{t}=$ $\mathrm{L} / \mathrm{V}$ where $\mathrm{V}$ is the average speed. The speed depends on the body size $\mathrm{M}$ (large or small) in proportion to $\mathrm{M}^{1 / 6}[5,6]$. The speed is also impacted by dehydration: on this phenomenon, the evidence is anecdotal and very familiar, because without water all animal activity slows down and dies. The rate of dehydration scales as the body surface (or $\mathrm{M}^{2 / 3}$ ), and so the body size $\mathrm{M}$ has a negative effect on $\mathrm{V}$, which is in proportion with $\mathrm{M}^{2 / 3}$, and is much stronger than the positive effect $\left(\mathrm{M}^{1 / 6}\right)$ associated with the design of animal locomotion.

\section{LIMITS TO SPEED}

Any discussion of trends in speed sports ultimately leads to questions about the future. What would the fastest speed be in ten years from now? [11]. A statistician, for example, would assert that the best way to predict the future is to extrapolate recorded trends (Figs 1a and 2a). A biologist may attempt to predict the future of speed sports by delving into muscle composition and contraction rates. These and many other ways of determining future maximum speeds of athletes are called into question, however, when factoring in individuals such as Usain Bolt. In 18 short months Bolt lowered the record by almost $2 \%$. It took nearly 16 years to accomplish the preceding $2 \%$ reduction in the record time, implying that sports evolution is challenging these conventional theories.

Despite all of the uncertainties surrounding predictions of the future, it is possible to predict from physics the speeds that cannot be surpassed by runners and swimmers. These predictions follow from the reality that animal and human locomotion has the same physics as an object that repeatedly (cyclically) falls forward [6, 7]. The taller object falls forward faster, and so the question of speed limits reduces to identifying the tallest object that can fall forward in the swimming pool and on the running track.

In the pool, the tallest object is a wave with an amplitude that cannot exceed the pool depth, which is $\mathrm{h}=2 \mathrm{~m}$. This is a shallow water wave [12], and its speed is $\mathrm{V}_{\max }=(\mathrm{gh})^{1 / 2}=4.43 \mathrm{~m} / \mathrm{s}$. The fastest swimmer would have to be strong enough to generate this wave, and big enough to surf on it. Whether such swimmers will emerge is not the point. Important is that there is a ceiling to speed in the pool, and that the record speeds of today [6] are practically the same as $\frac{1}{2} \mathrm{~V}_{\max }$.

The same holds for running speeds. The fastest object to cover the distance $\mathrm{x}=100 \mathrm{~m}$ would have to fall forward from a height of order $\mathrm{x} \sim 100 \mathrm{~m}$. The falling time would be $\mathrm{t}_{\min }=(2 \mathrm{x} / \mathrm{g})^{1 / 2}=4.52 \mathrm{~s}$, and the maximum speed would be $\mathrm{V}_{\max }=\mathrm{x} / \mathrm{t}_{\min }=22.1 \mathrm{~m} / \mathrm{s}$, which is approximately twice the current 
winning speeds in $100 \mathrm{~m}$ sprint. Whether athletes will become strong and tall enough to jump and fall forward from such heights is not the issue, and we are certainly not suggesting that humans will ever achieve this. The fact is that physics places an impenetrable ceiling on the running speeds that

keep rising, and that the top running speeds of today are practically equal to $\frac{1}{2} \mathrm{~V}_{\max }$, just like in swimming.

\section{ACKNOWLEDGMENT}

This research was conducted while the work of Prof. Bejan was supported by grants from the U.S. Air Force Office of Scientific Research and the National Science Foundation.

\section{REFERENCES}

[1] Hoppeler, H. \& Weibel, E.R., Scaling functions to body size: theories and facts. The Journal of Experimental Biology, 208, pp. 1573-1769, 2005. doi: http://dx.doi.org/10.1242/jeb.01630

[2] Schmidt-Nielsen, K., Scaling (Why is Animal Size so Important?), Cambridge University Press: Cambridge, UK, p. 112, 1984. doi: http://dx.doi.org/10.1017/CBO9781139167826

[3] Weibel, E.R., Symmorphosis, Harvard University Press: Harvard, MA, 2000.

[4] Ahlborn, B.K., Zoological Physics, Springer: Berlin, 2004.

[5] Bejan, A. \& Marden, J.H., Unifying constructal theory for scale effects in running, swimming and flying. The Journal of Experimental Biology, 209, pp. 238-248, 2006. doi: http://dx.doi. org/10.1242/jeb.01974

[6] Charles, J.D. \& Bejan, A., The evolution of speed, size and shape in modern athletics. The Journal of Experimental Biology, 212, pp. 2419-2425, 2009. doi: http://dx.doi.org/10.1242/ jeb.031161

[7] Bejan, A., Jones, E.C. \& Charles, J.D., The evolution of speed in athletics: why the fastest runners are black and swimmers white. International Journal of Design \& Nature and Ecodynamics, 5, pp. 199-211, 2010. doi: http://dx.doi.org/10.2495/DNE-V5-N3-199-211

[8] Vogt, P., Dictionary of Statistics and Methodology, Sage: Thousand Oaks, CA, 2005.

[9] Soong, T.T., Fundamentals of Probability and Statistics for Engineers, Wiley: Hoboken, 2004.

[10] FINA: Facility Rules; FR 3 Swimming Pools; FR 2.11 Water Temperature: 2011.

[11] Fleischer, A., ed., Vitesses Limites (Extreme Speeds), Le Genre Humain, Editions du Seuil: Paris, 2010.

[12] Sabersky, R.H., Acosta, A.J. \& Hauptmann, E.G., Fluid Flow, 2nd ed., Macmillan: New York, p. $385,1971$. 